\title{
Was this the First Case of Isospora belli in Saudi Arabia?
}

\author{
Majed H. Wakid \\ Department of Medical Laboratories Technology, Faculty of Applied Medical Sciences \\ King Fahd Medical Research Centre, Head of Diagnostic Parasitology Laboratory, Special Infectious Agents Unit \\ King Abdulaziz University, Jeddah, Saudi Arabia
}

\author{
Correspondence \\ Majed H. Wakid \\ Faculty of Applied Medical Sciences, \\ Department of Medical Laboratories \\ Technology, King Fahd Medical Research \\ Centre, Head of Diagnostic Parasitology \\ Laboratory, Special Infectious Agents Unit King \\ Abdulaziz University, Jeddah, \\ Saudi Arabia \\ e-M: mwakid@kau.edu.sa
}

$\begin{array}{ll}\text { Submission: } & 05 \text { Jan. } 2019 \\ \text { Accepted: } & 04 \text { May } 2019\end{array}$

\section{Citation}

Wakid MH. Was this the first case of Isospora belli in Saudi Arabia? JKAU Med Sci 2019; 26 (1): 1-2.

DOI: 10.4197/Med. 26-1.1

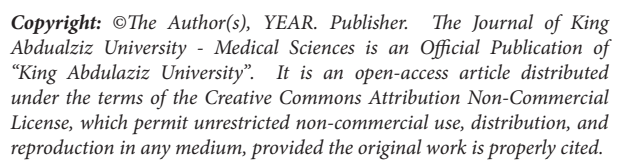

\section{Dear Editor-in-Chief,}

Isospora belli (now known as Cystoisospora belli) is a protozoan coccidian intestinal parasite belonging to the phylum Apicomplexa. It occurs worldwide, but most especially in hot tropical and subtropical climates. The risk of infection is greater in immunosuppressed and immunocompromised patients. The first case was documented in 1915; since then several outbreaks have been reported.

The mode of infection with isosporiasis occurs by ingestion of contaminated food or drinks containing the fully mature sporulated oocysts (disporous tetrazoic). After excystation of sporocysts in the small intestine, sporozoites invade epithelial cells and go under asexual and sexual multiplication to end up with formation of new non-infective oocysts, which can pass in the stool. Maturation of oocysts takes place in the environment outside the body within 1-2 days, depending on the level of oxygen, heat and humidity.

The main common symptoms include abdominal pain with severe non-bloody diarrhea that may result in dehydration and weight loss mostly in children and immunocompromised patients. The manifestation could be disseminated to involve the gallbladder, biliary tract, spleen and lymph nodes. A recent study identified a new stage and DNA of the parasite in blood samples of a patient with acquired immunodeficiency syndrome (AIDS).

During the year 1992, a loose stool sample from a male patient with AIDS was sent to the diagnostic parasitology laboratory at King Abdulaziz University Hospital in Jeddah. At that time, I was the senior laboratory technologist and Dr. Azza Negm (Died in 2008, may God have mercy on her) was the head of the laboratory. The laboratory protocol included the modified Kinyoun acid-fast staining as a routine test for all samples obtained from patients with HIV, cancer or having diarrhea or watery stool. The main concern was on Cryptosporidium, which is one of the common intestinal opportunistic coccidian parasites. We were surprised when the number of immature oocysts of $C$. belli was high enough to be easily detectable microscopically by direct wet smears. In modified Kinyoun's stained smears, we were able to identify three forms of oocysts containing one, two or diffused sporoblasts with size ranges between 25-30 X 10-15 $\mu \mathrm{m}$ (Fig. 1). In 2014, in cooperation with the Ministry of Health, we published a study on HIV patients. None of the patients was infected with C. belli.

To the best of our knowledge the case in 1992 is the first with cystoisosporiasis in Saudi Arabia but was not reported or published at that time. I still have stained and unstained stool smears, which will be directed for further examination using molecular tools 


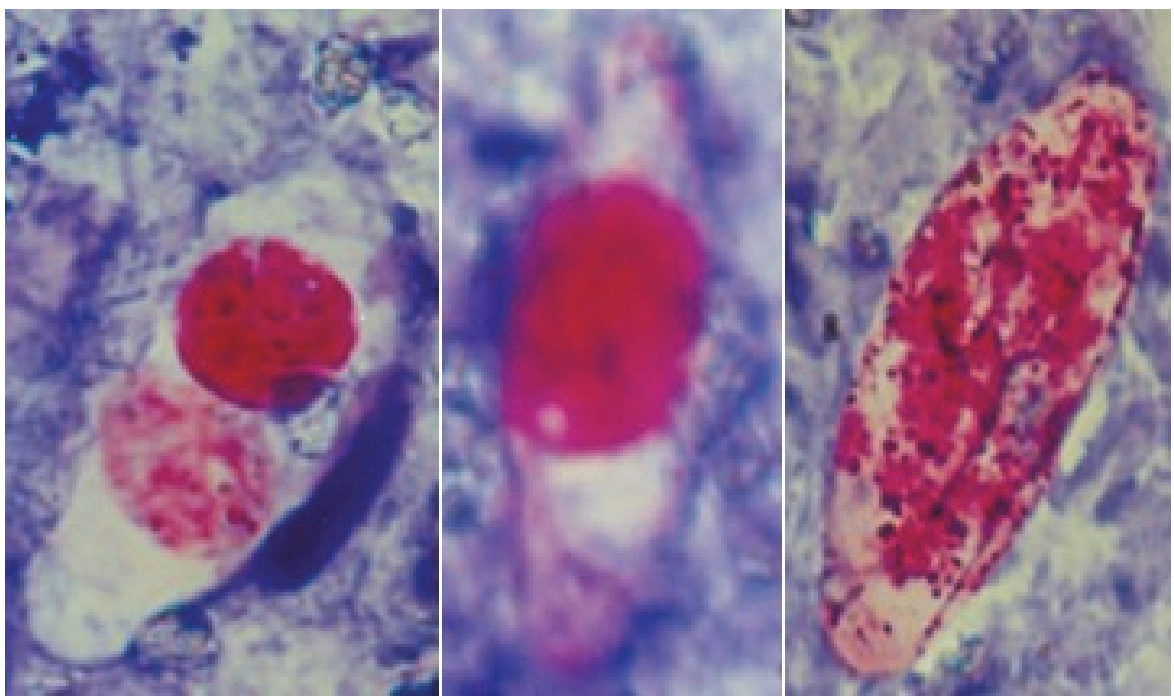

Figure 1. Three forms of the detected oocysts.

for genotypic identification. According to the findings presented in many recent studies in other countries, I believe that cystoisosporiasis in Saudi Arabia needs more attention than we currently devote.

\section{Conflicts of Interest}

The author has no conflict of interest.

\section{Disclosure}

The author did not receive any type of commercial support either in forms of compensation or financial for this study. The author has no financial interest in any of the products or devices, or drugs mentioned in this article.

\section{Ethical Approval}

Obtained.

\section{References}

[1] Rodriguez-Morales AJ, Castañeda-Hernández DM. Protozoa: Cystoisospora belli (Syn. Isospora belli). In book: Reference Module in Food Science 2019. DOI 10.1016/ B978-0-08-100596-5.22641-3.

[2] Wang ZD, Liu Q, Liu HH, Li S, Zhang L, Zhao YK, Xing-Quan Zhu XQ. Prevalence of Cryptosporidium, microsporidia and Isospora infection in HIV-infected people: a global systematic review and meta-analysis. Parasit Vectors 2018; 11(1): 28.

[3] Akateh C, Arnold CA, Benissan-Messan D, Michaels A, Black SM. Cystoisospora belli gallbladder infection in a liver transplant donor. Case Rep Infect Dis 2018: 3170238.
[4] Basyoni MMA, Elghobary HAF. Genotypic identification of Cystoisospora in immunocompromised patients using TMvariation analysis. Korean J Parasitol 2017; 55(6): 601-606.

[5] Lai KK, Goyne HE, Hernandez-Gonzalo D, Miller KA, Tuohy M, Procop GW, Lamps LW, Patil DT. Cystoisospora belli infection of the gallbladder in immunocompetent patients: a clinicopathologic review of 18 cases. Am J Surg Pathol 2016; 40(8): 1070-1074.

[6] Velásquez JN, di Risio CA, Etchart CB, Chertcoff AV, Nigro MG, Pantano ML, Ledesma BA, Vittar N, Carnevale S. First report of Cystoisospora belli parasitemia in a patient with acquired immunodeficiency syndrome. Acta Parasitol 2016; 61(1): 172-177.

[7] Sanad MM, Thagfan FA, Al Olayan EM, Almogren A, Al Hammaad A, Al-Mawash A, Mohamed AA. Opportunistic coccidian parasites among Saudi cancer patients presenting with diarrhea: prevalence and immune status. Res J Parasitol 2014; 9(2): 55-63.

[8] Wakid MH, Azhar El, Bakhsh HA, Ayoub HM, Al-Ghamdi AA. Isolation and genotyping of Cryptosporidium among HIV and non-HIV infected patients in Jeddah, Saudi Arabia. World J Med Sci 2014; 11 (1): 98-106. 